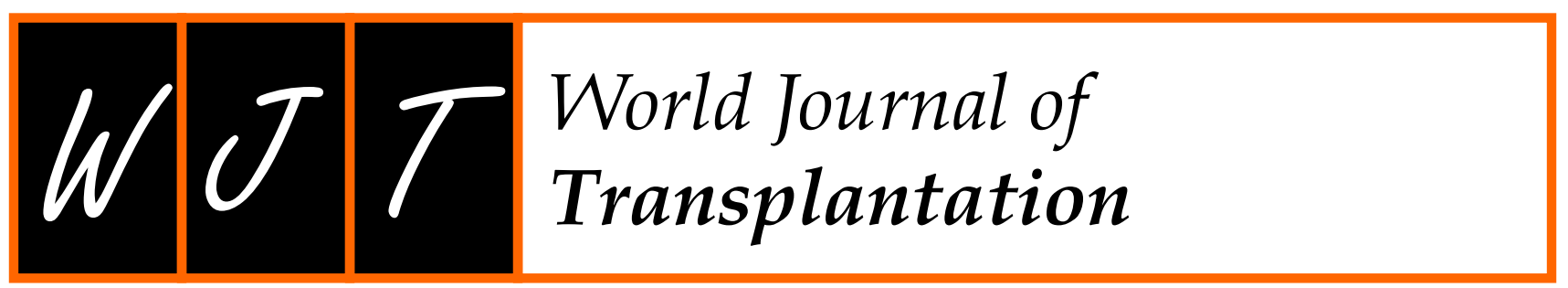

\title{
Immunometabolism: A target for the comprehension of immune response toward transplantation
}

\author{
Omar Domínguez-Amorocho, Tatiana Takiishi, Flavia Franco da Cunha, Niels Olsen Saraiva Camara
}

\author{
ORCID number: Omar Domínguez- \\ Amorocho (0000-0002-8989-0139); \\ Tatiana Takiishi \\ (0000-0003-2112-809X); Flávia \\ Franco da Cunha \\ (0000-0001-8209-7421); Niels Olsen \\ Saraiva Camara \\ (0000-0001-5436-1248).
}

Author contributions: DomínguezAmorocho $\mathrm{O}$ and Takiishi $\mathrm{T}$ contributed equally to this work, generated the figures and wrote the manuscript; da Cunha FF contributed to the writing of the manuscript; Camara NOS designed the aim of the editorial and wrote the manuscript.

\section{Supported by FAPESP doctoral fellowship grants (Omar Dominguez-Amorocho and Flavia Cunha), No. 2017/05264-7; and PNPd postdoctoral fellowship grant (Tatiana Takiishi).}

Conflict-of-interest statement: The authors certify that they have NO affiliations with or involvement in any organization or entity with any financial interest (such as honoraria; educational grants; participation in speakers' bureaus; membership, employment, consultancies, stock ownership, or other equity interest; and expert testimony or patent-licensing arrangements), or non-financial interest (such as personal or professional relationships, affiliations, knowledge or beliefs) in the subject matter or materials discussed in this manuscript.

Open-Access: This article is an open-access article which was selected by an in-house editor and fully peer-reviewed by external
Omar Domínguez-Amorocho, Tatiana Takiishi, Flavia Franco da Cunha, Niels Olsen Saraiva Camara, Department of Immunology, Biomedical Sciences Institute, University of São Paulo, São Paulo 05508-900, Brazil

Corresponding author: Niels Olsen Saraiva Câmara, MD, PhD, Research Scientist, Department of Immunology, Institute of Biomedical Sciences, University of São Paulo, Av. Prof. Lineu Prestes, 1730 Cid. Universitaria, Sao Paulo 05508-000, Brazil. niels@icb.usp.br Telephone: +55-11-30917388

\section{Abstract}

Organ transplantation is a life-saving procedure, however predicting graft survival is still challenging. Understanding immune-cell pathobiology is critical to the development of effective therapies to prevent rejection. Over the recent years it has become progressively evident that the complex nature of immune cell behavioral dynamics is strongly dependent on cellular metabolism, which in turn, relies on competition for nutrients, oxygen and metabolites with other immune cells and microbiota. Furthermore, the influence of the inflammatory state can lead to substantial changes in conditions within the tissue microenvironment. Considering the context of immunity, alterations in metabolic pathways (glycolysis, the tricarboxylic acid cycle, the pentose phosphate pathway, the fatty acid oxidation and synthesis, and the amino acid metabolic pathways) will influence the production of different sets of cytokines and affect transplantation outcome. It is now known that naïve, resting and effector cells acquire different metabolic profiles and studies have shown that specifically targeting some of these metabolic routes can prevent differentiation of effector $\mathrm{T}$ cells in favor of Tregs. Ultimately, to develop effective therapies that will prevent graft loss and understanding how cell metabolism impacts the fate and function of immune cells is now a critical point of discussion. The distinct metabolic features and requirements observed in effector and suppressive cell subsets offer promising opportunities for selective regulation of the immune responses in transplantation and will be discussed in this review.

Key words: Transplantation; Metabolic processes; Immune tolerance; Metabolic activation; Inflammatory response

CThe Author(s) 2019. Published by Baishideng Publishing Group Inc. All rights reserved.

Core tip: In this review we summarize the most recent findings on metabolic pathways involved in the determination of immune cell fate and highlight the relevance of 
reviewers. It is distributed in accordance with the Creative Commons Attribution Non Commercial (CC BY-NC 4.0) license, which permits others to distribute, remix, adapt, build upon this work non-commercially, and license their derivative works on different terms, provided the original work is properly cited and the use is non-commercial. See: http://creativecommons.org/licen ses/by-nc/4.0/

Manuscript source: Invited manuscript.

Received: September 12, 2018 Peer-review started: September 12, 2018

First decision: October 5, 2018

Revised: October 25, 2018

Accepted: January 28, 2019

Article in press: January 28, 2019

Published online: June 28, 2019

P-Reviewer: Zhang ZX, Hanna R, Boteon YL

S-Editor: Dou $Y$

L-Editor:E-Editor: Liu JH understanding how metabolic reprogramming is involved in the activation of dendritic cells and $\mathrm{T}$ cells, as well as development of strategies that target metabolic reprogramming to counteract effector cell activation in order to prevent graft failure.

Citation: Domínguez-Amorocho O, Takiishi T, da Cunha FF, Camara NOS.

Immunometabolism: A target for the comprehension of immune response toward

transplantation. World J Transplant 2019; 9(2): 27-34

URL: https://www.wjgnet.com/2220-3230/full/v9/i2/27.htm

DOI: https://dx.doi.org/10.5500/wjt.v9.i2.27

\section{INTRODUCTION}

Organ transplantation is a life-saving procedure, however predicting graft survival is still challenging. Sustaining transplantation tolerance is a key to overcome inflammatory challenges which lead to episodes of rejection or fibrosis and loss of graft function. Therefore, the goal of immunotherapies is to shape immune responses towards regulation to achieve long-term graft survival and eliminate the chronic use of immunosuppressants, which inflict severe side-effects.

Understanding immune-cell pathobiology is critical to develop new effective therapies that will prevent graft rejection. In allograft transplantation, the balance of immune responses towards alloantigen will depend on the coexistence of several mechanisms such as control in the frequency and function of alloreactive T cells via mechanisms of suppression such as expression of inhibitory molecules [e.g., programmed death (PD)-1], and induction of T regulatory cells (Tregs) ${ }^{[1]}$. Recently, it has also come to light that metabolic reprogramming impacts the fate and function of immune cells and might be a key determinant of transplantation outcome. Unlike other cells in the body, immune cells are capable of responding to their external environment and modulate their cellular behavior accordingly, for instance, availability of energetic substrates can influence cellular metabolism and in turn strongly affect immune cell fate towards acquisition of effector functions, quiescence, proliferation, etc $c^{[2]}$. This cellular metabolic reprogramming can be triggered in response to energy requirements for synthesis or decomposition of cell components, production of soluble factors such as cytokines, differentiation and cell survival, and it will condition the effector or regulatory properties of the immune cells ${ }^{[3]}$.

Undoubtedly, this new field of studies in immunometabolism will enable novel therapeutic approaches which increase chances of a successful transplantation outcome. The following sections will give some insight into general metabolic pathways and more specific metabolic signatures inherent to effector and suppressive cell subsets as well as some early work regarding immunometabolism in transplantation.

\section{MAIN METABOLIC PATHWAYS INVOLVED IN IMMUNE CELL FATE}

A very fine equilibrium of internal metabolites, such as reducing/oxidizing substrates, reactive oxygen species (ROS), as well as availability of growth factors and nutrients, weigh in to determine which metabolic pathway will be followed ${ }^{[2,3]}$. The concept of energy metabolism and nutrient sensing suggests that, after food breakdown, adenosine triphosphate (ATP) can be directly metabolized from nutrients or stored as alternative energy sources, such as proteins, glycogen or lipids ${ }^{[4]}$. Specifically considering immune cell function, changes in metabolic pathways have been associated to determination in proliferation, acquisition of effector function, specific cytokine signature and return to homeostasis. To simplify, in general six metabolic pathways are generally considered (Figure 1): (1) The glycolytic metabolic pathway; (2) The pentose phosphate pathway (PPP); (3) The tricarboxylic acid cycle (TCA); (4) Fatty acid oxidation (FAO); or (5) Synthesis; and(6) The amino acid metabolic pathway summarized from $\mathrm{O}^{\prime}$ Neill et al[5].

The glycolytic pathway, also named glycolysis, initiates with the transport of glucose from extracellular space by specialized transporters (such as Glut1), to ultimately generate pyruvate and other products after a series of enzymatic reactions. 


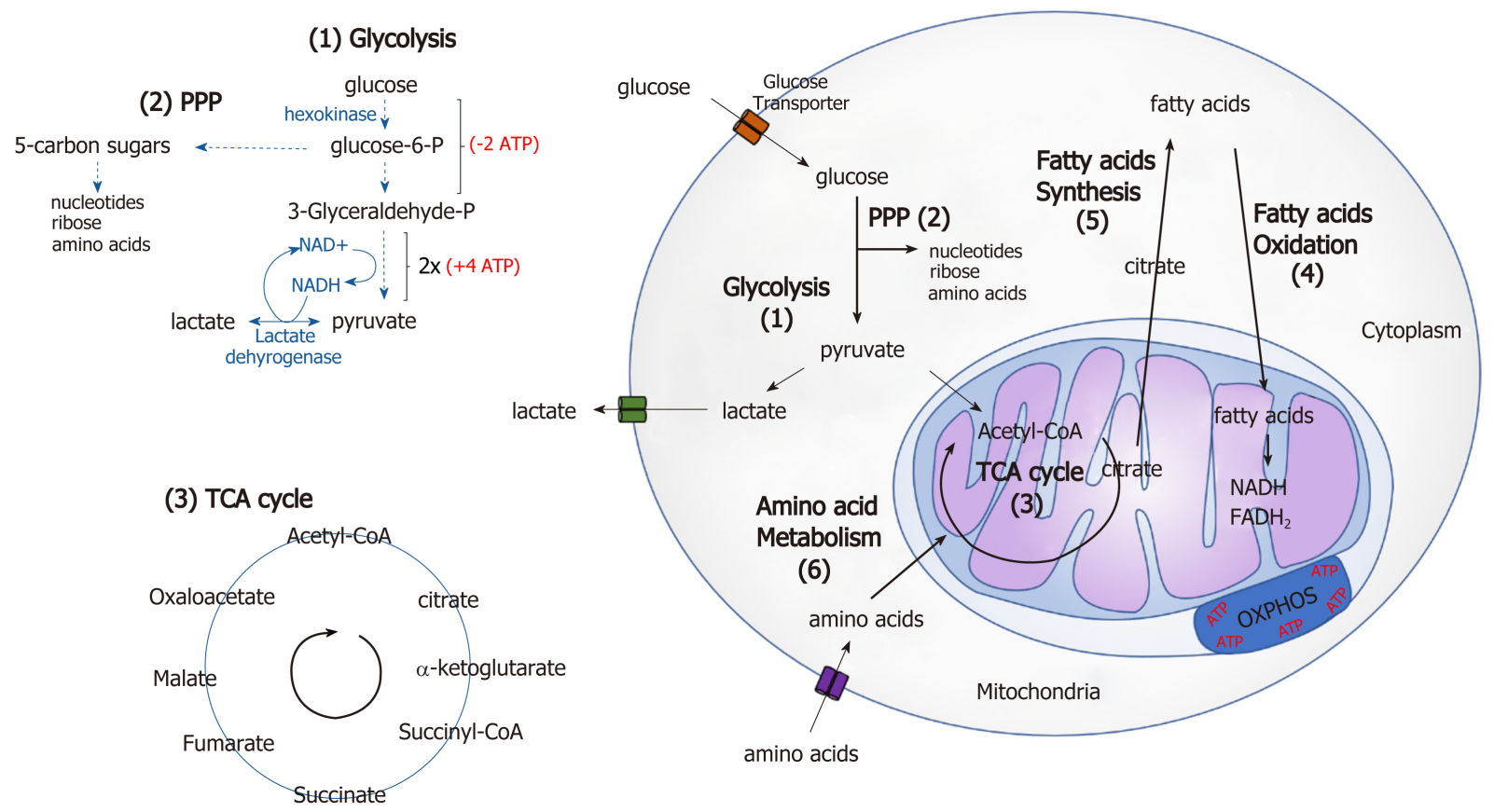

Figure 1 Six main metabolic pathways relevant for immune cell function. (1) Glycolysis is a process that occurs in the cytoplasm and involves conversion of glucose into pyruvate, (3) Which can either enter the tricarboxylic acid (TCA) cycle or be transformed into lactate and secreted. (2) The pentose phosphate pathway, is parallel to glycolysis and generates ribose for nucleotides, amino acids and nicotinamide adenine dinucleotide phosphate (NADPH), which is important for the synthesis of fatty acids and production of lipid ligands. (4) Fatty acid oxidation is a mitochondrial dependent aerobic process which consists on breaking down fatty acids into Acetyl-CoA units, generating NADH and FADH2, and driving ATP production from the E. (5) Fatty acid synthesis is a complex cytoplasmic process that is regulated by Acetyl-CoA, NADPH and fatty acid synthases to generate fatty acids. (6) Amino acid metabolism is very diverse, also important for cell growth and protein biosynthesis, as a consequence of the large number of different amino acids, which can feed different the carbon skeletons into pyruvate, acetyl $\mathrm{CoA}$, and the citric acid cycle, which enter the TCA cycle. TCA: Tricarboxylic acid; PPP: Pentose phosphate pathway; OXPHOS: Oxidative phosphorylation.

After entering the cell, glucose is phosphorylated by ATP to form glucose-6phosphate (G6P) in a reaction catalyzed by hexokinase. A series of enzymatic reactions degrade G6P to fructose-6-phosphate following by fructose-1,6bisphosphate and finally to glyceraldehyde-3-phosphate, which, in turn, is converted to pyruvate in the $\operatorname{cytosol}^{[6]}$. In the mitochondria, pyruvate is imported and converted to Acetyl-CoA, then integrating the TCA cycle, which leads to production of NADH and FADH2, cofactors for oxidoreductase enzymes in the electron transport chain (ETC), important in the generation of ATP. Alternatively, in the cytosol, the lactate dehydrogenase enzyme can convert pyruvate into lactate, reoxidizing NADH to $\mathrm{NAD}+$ which is necessary for glycolysis to continue ${ }^{\left[{ }^{[}\right]}$. In the absence of oxygen, glycolysis comes into action, catabolizing glucose into pyruvate, which is preferentially converted to lactate instead of Acetyl-CoA to enter the TCA cycle. Shift to glycolysis, even when oxygen is not a limitation is seen in some cases in a process known as aerobic glycolysis (fermentation) or Warburg effect, a process described by Otto Heinrich Warburg in which tumor cells tend to rely on glycolysis for ATP production rather than oxygen-dependent phosphorylation ${ }^{[7,8]}$.

The PPP functions in parallel to glycolysis and is an important source for reducing molecules (e.g., NADPH, required in anabolic reactions and critical to maintain redox balance under stress situations) and synthesis of pentoses (5-carbon sugars, important to maintain carbon homeostasis). The PPP reactions branches out into an oxidative and non-oxidative phase; the first oxidative phase converts G6P into NADPH, ribulose 5-phosphate and carbon dioxide, the second phase (non-oxidative) generates ribose 5-phosphate for the synthesis of nucleic acids and other sugar phosphate precursors used to build amino acids ${ }^{[0]}$.

Mitochondrial FAO is a catabolic pathway that generates necessary products for the cell to produce energy, such as Acetyl-CoA, NADH+ and FADH2. The FAO is composed by two steps: the "activation" and the oxidation. The first step occurs in the cytosol and it is the formation of a fatty acid acyl-CoA with the consumption of ATP. The second step is called $\beta$-oxidation and generates quantities of Acetyl-CoA, NADH and FADH2. These products then enter the TCA cycle and the ETC, where they can be used for the generation of $\mathrm{ATP}^{\left[{ }^{[}\right]}$. On the other hand cells need lipids to produce cell membranes and other structures necessary for cell growth and proliferation so the 
fatty acid synthesis (FAS) pathway converts intermediate products from glycolysis and TCA in acetyl-coA that is used to generate lipids ${ }^{[10]}$. In the mitochondria, citrate is synthesized from Acetyl-CoA and oxaloacetate, which is exported to the cytosol where it is cleaved to yield acetyl-CoA and oxaloacetate, then cytosolic Acetyl-CoA, is converted to Malonil-CoA and, by the effect of the fatty acid synthase, to Palmitate. Palmitate or palmitic acid is the most common saturated fatty acid in the human organism, and important for the composition of membrane phospholipids, substrate for the acylation of proteins, cholesterol synthesis and adipose triacylglycerols ${ }^{[6,11]}$.

\section{CROSSTALK BETWEEN CELL METABOLISM AND IMMUNE RESPONSES}

The interplay between metabolic dysfunction and immune mechanisms involved in inflammation are being exposed by a growing number of studies and this knowledge is reshaping the understanding of what appeared to be independently functional systems of immunity and metabolism ${ }^{[12]}$.

Dendritic cells (DCs) are a heterogeneous cell population key to immune homeostasis as they control activation and polarization of effector $\mathrm{T}$ cell responses and Treg differentiation. During DC maturation, the metabolic profile of precursors and differentiating DCs is eschewed, shifting from glycolysis to oxidative phosphorylation (OXPHOS), process that involves ROS, as well as an increase in expression of mitochondrial respiratory enzymes, ATP content and antioxidant capacity ${ }^{[13]}$. In activated DCs, glycolytic intermediates can also enter into the PPP, which support biosynthesis of nucleotides for increased protein output and the generation of NADPH, and the TCA cycle and support lipid membrane production and macromolecule biosynthesis ${ }^{[13,14]}$. Tolerogenic DCs (tolDCs), present a more active catabolic pathway, fatty acid metabolism, OXPHOS with increased respiratory capacity and highest mitochondrial oxidative activity as well as glycolytic capacity in comparison to mature DCs ${ }^{[14]}$.

It is known that naive $\mathrm{T}$ cells have lower metabolic requirements, hence favor glycolysis and TCA cycle ${ }^{[15]}$. Once activated T cells undergo metabolic reprogramming which is believed necessary for cells to sustain the biosynthesis of lipids, proteins and nucleic acids required for cell proliferation and effector molecules, therefore, a change from OXPHOS in naïve or memory cells to increased glycolysis is observed in effector T cells ${ }^{[16]}$ (Figure 2). Thus, increase in glycolysis, PPP, glutamine metabolism, combined with synthesis of cellular components characterizes early cell activation $^{[7,15,17]}$. In general, in vitro studies have indicated that glycolysis is very important for effector cell development, evidenced also by data showing that GLUT1 deficiency impairs CD4+ effector function and proliferation while Tregs are enriched and functionally unaffected ${ }^{[18,19]}$. In a similar manner, glutamate metabolism is also involved in the differentiation of Th1 and Th17 effector T cells but does not seem to be critical for Tregs ${ }^{[18,20]}$. Effector $\mathrm{T}$ cells undergoing enhanced proliferation, including some subtypes of $\mathrm{T}$ helper cells, and CD8+ T cells, increase glycolysis and glutaminolysis as a mechanism to meet the increased metabolic demands of cell growth as well as optimize the production of proinflammatory cytokines, such as IL-2 and IFN- $\gamma^{[21]}$. In Tregs glycolysis modulates the expression of FOXP3, as it was demonstrated that 2-DG (2-deoxy-d-glucose)-glycolysis inhibition in human T cells lead to decreased IL-2-IL-2R-STAT5 signaling, consequently limiting the generation of functionally suppressive Treg cells ${ }^{[22]}$. Furthermore, activation of the glycolyticlipogenic metabolism seems to be involved in the Th17/Treg balance, for example, Acetyl-CoA carboxylase 1 (ACC1)-mediated de novo FAS affects Th17 cell differentiation but not Treg cells ${ }^{[23-25]}$. Potentially, drugs such as soraphen A (ACCspecific inhibitor) could be tested in preclinical animal models to verify improvement of graft survival.

In regards to lipids, they are essential components for the structure of cell membrane, which must be duplicated in preparation for each cell division, as well as important energy sources metabolized through beta-oxidation, not surprisingly, lipids are easily accessible to immune cells in adipose tissue which abundantly surrounds lymph nodes ${ }^{[26]}$.

Lastly, fatty acid metabolism is involved in both CD4 and CD8 cell function. For instance, a study demonstrated that the suppression of FAS by inhibition of ACC1 restrained the generation of pro-inflammatory Th17 cells, whilst favoring the differentiation of FoxP3+ Tregs ${ }^{[23]}$ while in case of memory CD8 T cells, activation favors neo-synthesis of fatty acids to support $\mathrm{FAO}^{[27]}$.

In summary, differentiation, activation and effector function of immune cells seem to be directly or indirectly oriented by shifts in metabolic pathway. Thus, when 


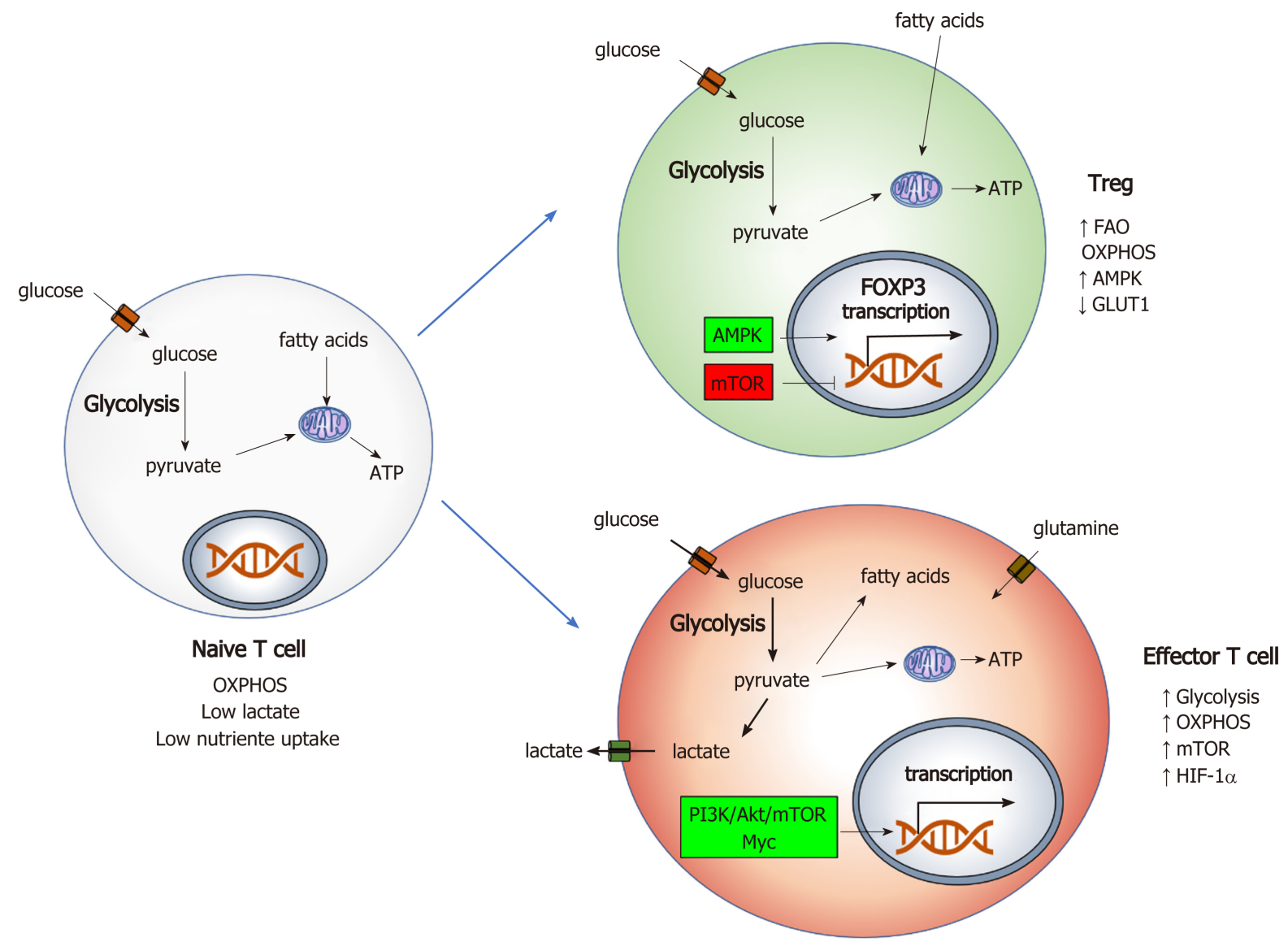

Figure 2 Main metabolic pathways in T cells - Naïve T cells are characterized by lower energy requirement, low glucose uptake and mainly use oxidative phosphorylation for energy generation. Once T cells are activated there is a switch in metabolic state which is accompanied by changes via the PI3K/Akt/mTOR axis and Myc. Increase in glycolysis and oxidative phosphorylation (OXPHOS) are characteristic in activated effector T cells, increase in glutamine uptake and fatty acid synthesis is also observed. In contrast, Tregs have metabolic features comparative to naïve T cells, producing energy by lipid oxidation and OXPHOS in mitochondria for the generation of adenosine triphosphate ${ }^{[7,42,43]}$. ATP: Adenosine triphosphate; AMPK: Adenosine monophosphate activated protein kinase; OXPHOS: Oxidative phosphorylation; FAO: Fatty acid oxidation.

considering metabolic parameters that affect immune cell fate, a variety factors will influence the tissue microenvironment such as: nutrient competition, oxygen consumption and metabolite production from tissue, immune cells and microbiota as well as the inflammatory state of the host ${ }^{[28,29]}$.

\section{TARGETING METABOLIC PATHWAYS IN TRANSPLANTATION}

Solid organ transplantation is most-often the last resource for patients who suffer from end-stage organ disease, however, long-term acceptance and survival of transplanted tissues and organs is currently limited mainly due to immune-mediated mechanisms ${ }^{[30]}$. A great deal of effort has been dedicated to understanding the mechanisms underlying rejection by effector and emerging evidence does suggest a prominent role for nutritional and metabolic substrates on immune responses.

In transplantation, during which the tissue obligatorily goes through surgical trauma, lack of oxygenation or damage from reperfusion, the injury causes oxidative stress (OS) and release of Damage-associated molecular patterns and danger signals from necrotic cell death, which act as endogenous activators of innate immune mechanisms that promote inflammatory tissue damage and metabolic alterations in immune cells ${ }^{[3]}$. This signaling cascade will provoke the initial infiltration of cells into the allograft, followed by migration to lymph nodes, where T cells and DCs will initiate and allow propagation of allo-specific immune responses ${ }^{[28,29,32]}$. In the process of following antigenic activation, cells require a major shift in energy requirement as they change from a quiescent state to active-cytokine producing and proliferating immune cells, thus, this metabolic reprogramming includes balance between energy production and consumption based on availability of nutritional derived components, 
mitochondrial or anaerobic respiration ${ }^{[16]}$.

Regarding DC regulation, pharmacological intervention such as activation of AMPK signaling by peroxisome proliferator-activated receptor gamma coactivator (PGC) and Resveratrol to enhance PGC-1a activity has been demonstrated to generate tolDCs ${ }^{[33-35]}$, that have crucial role in inducing tolerance to the graft. DCs treated with Resveratrol showed reduced capacity to stimulate allogenic $\mathrm{T}$ cells and to induce CD4+ T cell migration ${ }^{[35]}$. Also, metabolic products like ATP may be recognized as a danger signal, whilst upon ATP degradation leads to decrease in pro-inflammatory signalling, regulating activation of antigen presenting cells or Treg cells ${ }^{[3,37]}$.

Studies have shown that $\mathrm{T}$ cell activation and effector responses require metabolic reprogramming which relies glycolysis and glutaminolysis pathways ${ }^{[38-40]}$, now researchers are investing whether intervening in this specific pathways can ameliorate graft survival. In a model of hematopoietic cell transplantation, Nguyen and colleagues demonstrated that alloantigen $\mathrm{T}$ cells demand on glycolysis for activation and GVHD (graft versus host disease) induction. In a pre-clinical murine GVHD model, blockage of glycolysis by use of rapamycin which inhibits mTORC1 or mTOR knockout mice, as well as use of 3-(3-pyridinyl)-1-(4-pyridinyl)-2-propen-1-one (3PO), a specific inhibitor of pathway6-phosphofructo-2-kinase/fructose-2,6biphosphatase 3, which also limits glycolysis, increased survival of mice ${ }^{[4]]}$.

Using murine models of skin and heart allograft transplantations, another study showed the effects of glycolysis and glutamine metabolism inhibition. Using a combination of 2-DG, 6-diazo-5-oxo-L-norleucine (glutamine metabolism inhibitor) and the anti-type II diabetes drug metformin, the group demonstrated an inhibition of allo-specific CD4+ and CD8+ T cell responses, preventing or delaying rejection in fully mismatched skin and heart allograft transplantation models ${ }^{[40]}$.

In summary, these very fresh data seem to indicate that it is possible to hamper alloantigen-induced activation of effector responses by targeting some metabolic pathways.

\section{CONCLUSION}

Immunometabolism is a very new field to be explored, studies which have specifically targeted metabolic pathways in transplant models are only beginning to emerge. However, based on findings that it is possible to change metabolic reprogramming of DCs and T cells it may be possible to promote transplantation tolerance and avoid rejection. Most studies so far have focused in inhibition of glycolysis and the effects in $\mathrm{T}$ cells; this seems to improve graft survival in murine models, however long-term effects of this type of therapies and in the full components of the immune system have yet to be understood in order to declare metabolic intervention safe. It is important to continue research and find distinct metabolic signatures in different phases of DC and alloreactive $\mathrm{T}$ cell activation to specifically target immune alloreactive effector responses without deleterious side-effects.

\section{REFERENCES}

1 Alegre ML. What's new in transplantation tolerance? Curr Opin Organ Transplant 2018; 23: 63-65 [PMID: 29189414 DOI: 10.1097/MOT.0000000000000493]

2 Buck MD, Sowell RT, Kaech SM, Pearce EL. Metabolic Instruction of Immunity. Cell 2017; 169: 570586 [PMID: 28475890 DOI: 10.1016/j.cell.2017.04.004]

3 Domblides C, Lartigue L, Faustin B. Metabolic Stress in the Immune Function of T Cells, Macrophages and Dendritic Cells. Cells 2018; 7 [PMID: 29966302 DOI: 10.3390/cells7070068]

4 Iyer A, Brown L, Whitehead JP, Prins JB, Fairlie DP. Nutrient and immune sensing are obligate pathways in metabolism, immunity, and disease. FASEB J 2015; 29: 3612-3625 [PMID: 26065858 DOI: 10.1096/fj.15-271155]

5 O'Neill LA, Kishton RJ, Rathmell J. A guide to immunometabolism for immunologists. Nat Rev Immunol 2016; 16: 553-565 [PMID: 27396447 DOI: 10.1038/nri.2016.70]

6 Palmer CS, Ostrowski M, Balderson B, Christian N, Crowe SM. Glucose metabolism regulates T cell activation, differentiation, and functions. Front Immunol 2015; 6: 1 [PMID: 25657648 DOI: 10.3389/fimmu.2015.00001]

7 Almeida L, Lochner M, Berod L, Sparwasser T. Metabolic pathways in T cell activation and lineage differentiation. Semin Immunol 2016; 28: 514-524 [PMID: 27825556 DOI: 10.1016/j.smim.2016.10.009]

8 Warburg O, Wind F, Negelein E. THE METABOLISM OF TUMORS IN THE BODY. J Gen Physiol 1927; 8: 519-530 [PMID: 19872213 DOI: 10.1085/jgp.8.6.519]

9 Pearce EL, Pearce EJ. Metabolic pathways in immune cell activation and quiescence. Immunity 2013; 38: 633-643 [PMID: 23601682 DOI: 10.1016/j.immuni.2013.04.005]

10 Stincone A, Prigione A, Cramer T, Wamelink MM, Campbell K, Cheung E, Olin-Sandoval V, Grüning NM, Krüger A, Tauqeer Alam M, Keller MA, Breitenbach M, Brindle KM, Rabinowitz JD, Ralser M. The return of metabolism: biochemistry and physiology of the pentose phosphate pathway. Biol Rev Camb Philos Soc 2015; 90: 927-963 [PMID: 25243985 DOI: 10.1111/brv.12140] 
11 Weinberg SE, Sena LA, Chandel NS. Mitochondria in the regulation of innate and adaptive immunity. Immunity 2015; 42: 406-417 [PMID: 25786173 DOI: 10.1016/j.immuni.2015.02.002]

12 Priyadharshini B, Turka LA. T-cell energy metabolism as a controller of cell fate in transplantation. Curr Opin Organ Transplant 2015; 20: 21-28 [PMID: 25563988 DOI: 10.1097/MOT.0000000000000149]

13 Sim WJ, Ahl PJ, Connolly JE. Metabolism Is Central to Tolerogenic Dendritic Cell Function. Mediators Inflamm 2016; 2016: 2636701 [PMID: 26980944 DOI: 10.1155/2016/2636701]

14 Malinarich F, Duan K, Hamid RA, Bijin A, Lin WX, Poidinger M, Fairhurst AM, Connolly JE. High mitochondrial respiration and glycolytic capacity represent a metabolic phenotype of human tolerogenic dendritic cells. J Immunol 2015; 194: 5174-5186 [PMID: 25917094 DOI: 10.4049/jimmunol.1303316] Buck MD, O'Sullivan D, Pearce EL. T cell metabolism drives immunity. J Exp Med 2015; 212: 1345-1360 [PMID: 26261266 DOI: 10.1084/jem.20151159]

16 Degauque N, Brosseau C, Brouard S. Regulation of the Immune Response by the Inflammatory Metabolic Microenvironment in the Context of Allotransplantation. Front Immunol 2018; 9: 1465 [PMID: 29988548 DOI: 10.3389/fimmu.2018.01465]

17 Loftus RM, Finlay DK. Immunometabolism: Cellular Metabolism Turns Immune Regulator. J Biol Chem 2016; 291: 1-10 [PMID: 26534957 DOI: 10.1074/jbc.R115.693903]

18 Macintyre AN, Gerriets VA, Nichols AG, Michalek RD, Rudolph MC, Deoliveira D, Anderson SM, Abel ED, Chen BJ, Hale LP, Rathmell JC. The glucose transporter Glut1 is selectively essential for CD4 T cell activation and effector function. Cell Metab 2014; 20: 61-72 [PMID: 24930970 DOI: 10.1016/j.cmet.2014.05.004]

19 Shi LZ, Wang R, Huang G, Vogel P, Neale G, Green DR, Chi H. HIF1alpha-dependent glycolytic pathway orchestrates a metabolic checkpoint for the differentiation of TH17 and Treg cells. J Exp Med 2011; 208: 1367-1376 [PMID: 21708926 DOI: 10.1084/jem.20110278]

20 Nakaya M, Xiao Y, Zhou X, Chang JH, Chang M, Cheng X, Blonska M, Lin X, Sun SC. Inflammatory T cell responses rely on amino acid transporter ASCT2 facilitation of glutamine uptake and mTORC1 kinase activation. Immunity 2014; 40: 692-705 [PMID: 24792914 DOI: 10.1016/j.immuni.2014.04.007]

21 MacIver NJ, Michalek RD, Rathmell JC. Metabolic regulation of T lymphocytes. Annu Rev Immunol 2013; 31: 259-283 [PMID: 23298210 DOI: 10.1146/annurev-immunol-032712-095956]

22 De Rosa V, Galgani M, Porcellini A, Colamatteo A, Santopaolo M, Zuchegna C, Romano A, De Simone S, Procaccini C, La Rocca C, Carrieri PB, Maniscalco GT, Salvetti M, Buscarinu MC, Franzese A, Mozzillo E, La Cava A, Matarese G. Glycolysis controls the induction of human regulatory T cells by modulating the expression of FOXP3 exon 2 splicing variants. Nat Immunol 2015; 16: 1174-1184 [PMID: 26414764 DOI: 10.1038/ni.3269]

23 Berod L, Friedrich C, Nandan A, Freitag J, Hagemann S, Harmrolfs K, Sandouk A, Hesse C, Castro CN, Bähre H, Tschirner SK, Gorinski N, Gohmert M, Mayer CT, Huehn J, Ponimaskin E, Abraham WR, Müller R, Lochner M, Sparwasser T. De novo fatty acid synthesis controls the fate between regulatory T and T helper 17 cells. Nat Med 2014; 20: 1327-1333 [PMID: 25282359 DOI: 10.1038/nm.3704]

24 Chang CH, Curtis JD, Maggi LB, Faubert B, Villarino AV, O'Sullivan D, Huang SC, van der Windt GJ, Blagih J, Qiu J, Weber JD, Pearce EJ, Jones RG, Pearce EL. Posttranscriptional control of T cell effector function by aerobic glycolysis. Cell 2013; 153: 1239-1251 [PMID: 23746840 DOI: 10.1016/j.cell.2013.05.016]

25 Gerriets VA, Kishton RJ, Nichols AG, Macintyre AN, Inoue M, Ilkayeva O, Winter PS, Liu X, Priyadharshini B, Slawinska ME, Haeberli L, Huck C, Turka LA, Wood KC, Hale LP, Smith PA, Schneider MA, MacIver NJ, Locasale JW, Newgard CB, Shinohara ML, Rathmell JC. Metabolic programming and PDHK1 control CD4+ T cell subsets and inflammation. J Clin Invest 2015; 125: 194207 [PMID: 25437876 DOI: 10.1172/JCI76012]

26 Pond CM, Mattacks CA. Interactions between adipose tissue around lymph nodes and lymphoid cells in vitro. J Lipid Res 1995; 36: 2219-2231 [PMID: 8576648]

27 O'Sullivan D, van der Windt GJ, Huang SC, Curtis JD, Chang CH, Buck MD, Qiu J, Smith AM, Lam WY, DiPlato LM, Hsu FF, Birnbaum MJ, Pearce EJ, Pearce EL. Memory CD8(+) T cells use cell-intrinsic lipolysis to support the metabolic programming necessary for development. Immunity 2014; 41: 75-88 [PMID: 25001241 DOI: 10.1016/j.immuni.2014.06.005]

28 Wrenshall L. Role of the microenvironment in immune responses to transplantation. Springer Semin Immunopathol 2003; 25: 199-213 [PMID: 12955467 DOI: 10.1007/s00281-003-0138-y]

29 Martinez-Llordella M, Mastoridis S. Immunometabolism: Novel Monitoring and Therapeutic Approach in Transplantation. Transplantation 2018; 102: 187-188 [PMID: 29084025 DOI: 10.1097/TP.0000000000001988]

30 Garakani R, Saidi RF. Recent Progress in Cell Therapy in Solid Organ Transplantation. Int J Organ Transplant Med 2017; 8: 125-131 [PMID: 28924460]

31 Rock KL, Kono H. The inflammatory response to cell death. Annu Rev Pathol 2008; 3: 99-126 [PMID: 18039143 DOI: 10.1146/annurev.pathmechdis.3.121806.151456]

32 Rogers NM, Ferenbach DA, Isenberg JS, Thomson AW, Hughes J. Dendritic cells and macrophages in the kidney: a spectrum of good and evil. Nat Rev Nephrol 2014; 10: 625-643 [PMID: 25266210 DOI: 10.1038/nrneph.2014.170]

33 Everts B, Pearce EJ. Metabolic control of dendritic cell activation and function: recent advances and clinical implications. Front Immunol 2014; 5: 203 [PMID: 24847328 DOI: 10.3389/fimmu.2014.00203]

34 Kelly B, O'Neill LA. Metabolic reprogramming in macrophages and dendritic cells in innate immunity. Cell Res 2015; 25: 771-784 [PMID: 26045163 DOI: 10.1038/cr.2015.68]

35 Svajger U, Obermajer N, Jeras M. Dendritic cells treated with resveratrol during differentiation from monocytes gain substantial tolerogenic properties upon activation. Immunology 2010; 129: 525-535 [PMID: 20002210 DOI: 10.1111/j.1365-2567.2009.03205.x]

36 Bours MJ, Swennen EL, Di Virgilio F, Cronstein BN, Dagnelie PC. Adenosine 5'-triphosphate and adenosine as endogenous signaling molecules in immunity and inflammation. Pharmacol Ther 2006; 112 358-404 [PMID: 16784779 DOI: 10.1016/j.pharmthera.2005.04.013]

37 Deaglio S, Dwyer KM, Gao W, Friedman D, Usheva A, Erat A, Chen JF, Enjyoji K, Linden J, Oukka M, Kuchroo VK, Strom TB, Robson SC. Adenosine generation catalyzed by CD39 and CD73 expressed on regulatory T cells mediates immune suppression. $J$ Exp Med 2007; 204: 1257-1265 [PMID: 17502665 DOI: 10.1084/jem.20062512]

38 Wang R, Dillon CP, Shi LZ, Milasta S, Carter R, Finkelstein D, McCormick LL, Fitzgerald P, Chi H, Munger J, Green DR. The transcription factor Myc controls metabolic reprogramming upon T lymphocyte activation. Immunity 2011; 35: 871-882 [PMID: 22195744 DOI: 10.1016/j.immuni.2011.09.021] 
39 Nguyen HD, Chatterjee S, Haarberg KM, Wu Y, Bastian D, Heinrichs J, Fu J, Daenthanasanmak A, Schutt S, Shrestha S, Liu C, Wang H, Chi H, Mehrotra S, Yu XZ. Metabolic reprogramming of alloantigen-activated T cells after hematopoietic cell transplantation. J Clin Invest 2016; 126: 1337-1352 [PMID: 26950421 DOI: 10.1172/JCI82587]

40 Lee CF, Lo YC, Cheng CH, Furtmüller GJ, Oh B, Andrade-Oliveira V, Thomas AG, Bowman CE, Slusher BS, Wolfgang MJ, Brandacher G, Powell JD. Preventing Allograft Rejection by Targeting Immune Metabolism. Cell Rep 2015; 13: 760-770 [PMID: 26489460 DOI: 10.1016/j.celrep.2015.09.036]

41 Nguyen HD, Kuril S, Bastian D, Yu XZ. T-Cell Metabolism in Hematopoietic Cell Transplantation. Front Immunol 2018; 9: 176 [PMID: 29479351 DOI: 10.3389/fimmu.2018.00176]

42 Galgani M, De Rosa V, La Cava A, Matarese G. Role of Metabolism in the Immunobiology of Regulatory T Cells. J Immunol 2016; 197: 2567-2575 [PMID: 27638939 DOI: 10.4049/jimmunol.1600242]

43 Franchina DG, He F, Brenner D. Survival of the fittest: Cancer challenges T cell metabolism. Cancer Lett 2018; 412: 216-223 [PMID: 29074426 DOI: 10.1016/j.canlet.2017.10.014] 


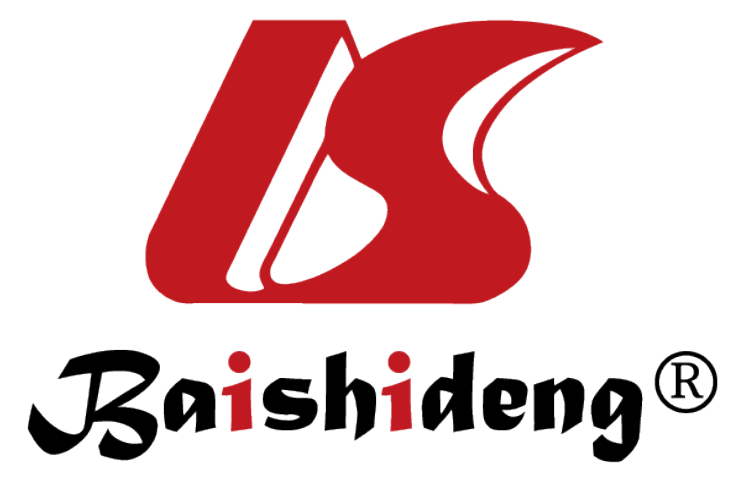

Published By Baishideng Publishing Group Inc

7041 Koll Center Parkway, Suite 160, Pleasanton, CA 94566, USA

Telephone: +1-925-2238242

Fax: +1-925-2238243

E-mail: bpgoffice@wjgnet.com

Help Desk:https://www.f6publishing.com/helpdesk

https://www.wjgnet.com

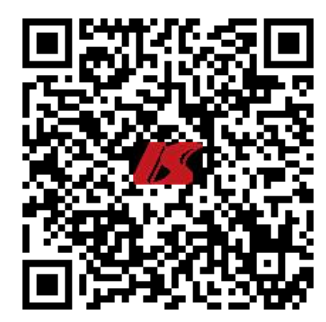

